\title{
Residual genetic variability in domesticated populations of the Pacific blue shrimp (Litopenaeus stylirostris) of New Caledonia, French Polynesia and Hawaii and some management recommendations
}

\author{
Emmanuel Goyard $^{\mathrm{a}, *}$, Sophie Arnaud ${ }^{\mathrm{b}}$, Vincent Vonau ${ }^{\mathrm{b}}$, Vincent Bishoff ${ }^{\mathrm{b}}$, Olivier Mouchel ${ }^{\mathrm{b}}$, \\ Dominique Pham ${ }^{\mathrm{a}}$, Jim Wyban ${ }^{\mathrm{c}}$, Pierre Boudry ${ }^{\mathrm{d}}$, AQUACOP ${ }^{\mathrm{b}}$ \\ ${ }^{a}$ Laboratoire d'Aquaculture de Calédonie, IFREMER, BP 2059, 98846 Nouméa cedex, New Caledonia \\ ${ }^{b}$ Laboratoire d'Aquaculture Tropicale, IFREMER, BP 7004, 98719 Taravao, Tahiti, French Polynesia \\ ${ }^{c}$ HHAInc., PO Box 1095, Kurtistown, HI 96760, USA \\ ${ }^{d}$ Laboratoire Génétique et Pathologie, IFREMER, 17390 La Tremblade, France
}

Received 15 December 2002; accepted 16 July 2003

\begin{abstract}
The Latin American shrimp Litopenaeus stylirostris was introduced in three different Pacific islands (Tahiti, New Caledonia via Tahiti, and Hawaii) and hatchery-propagated for 7-25 generations to develop shrimp farming based on these domesticated stocks. Three microsatellite markers have been used in an attempt to assess the genetic bases of the populations available to start a selective breeding program. The comparison of eight hatchery stocks (five New Caledonian, two Hawaiian and one Tahitian stocks) and one wild Ecuadorian population showed a much lower variability in the domesticated stocks than in the wild population, especially in New Caledonia and Tahiti (2-3.7 vs. 14-27 alleles per locus; $20-60 \%$ vs. $90 \%$ expected heterozygosity). The Tahitian and the New Caledonian stocks share the same alleles, suggesting that the loss of alleles occurred during the common past of these populations. On the contrary, New Caledonian and Hawaiian populations share only one common allele at the three loci studied. Although the low genetic variability and the resulting inbreeding of the New Caledonian stocks do not seem to affect their present performance, the results of this study demonstrate the usefulness of the introduction of new stocks in order to increase the potential responses to new controlled or uncontrolled selective pressures. The introduction in New Caledonia of the Hawaiian domesticated stocks, which would provide the local shrimp industry with $40 \%$ of the allelic diversity of the species, is advised and preferred to the one of wild animals in order to take advantage (i) of the spontaneous selection which occurred during domestication and (ii) of their favourable sanitary "specific pathogen free" status (no presence of four viruses: WSV, YHV, IHHNV, TSV) which limits the risk of introduction of pathogens.
\end{abstract}

(c) 2003 Published by Elsevier SAS.

Résumé

Variabilité génétique résiduelle au sein des populations domestiquées de crevette Litopenaeus stylirostris de Nouvelle-Calédonie, de Polynésie française et d'Hawaï ; quelques recommandations de gestion. La crevette d'Amérique latine Litopaenus stylirostris a été introduite dans trois îles du Pacifique (à Tahiti, en Nouvelle-Calédonie via Tahiti, et à Hawaii), et a été ensuite reproduite en écloserie pendant 7 à 25 générations à des fins d'aquaculture. Trois marqueurs microsatellites ont été utilisés pour évaluer les bases génétiques des populations disponibles pour le démarrage d'un programme d'amélioration génétique. L'étude comparative de 8 populations domestiquées (cinq néo-calédoniennes, deux hawaiiennes et une tahitienne) et d'une population sauvage d'Equateur révèle une variabilité très réduite dans les populations d'élevage, en particulier en Nouvelle-Calédonie et à Tahiti ( 2 à 3.7 allèles par locus au lieu de 14 à 27 en population sauvage ; $20 \%$ à $60 \%$ d'hétérozygotie au lieu de $90 \%$ ). Les souches tahitiennes et calédoniennes disposent des mêmes allèles, ce qui suggère que la perte d'allèles a eu lieu lors de l'histoire commune des ces populations. A l'inverse, les populations néo-calédoniennes et hawaiiennes n'ont en commun qu'un seul allèle sur les 3 locus étudiés. Bien que la très faible variabilité génétique du cheptel calédonien ne semble pas affecter ses performances actuelles, les résultats de cette étude démontrent l'utilité de l'introduction de variabilité afin d'augmenter la capacité de réponse à de nouvelles pressions de sélection (contrôlées ou non). L'introduction des souches hawaiiennes en Nouvelle-Calédonie qui permettrait à la

\footnotetext{
* Corresponding author.

E-mail address: egoyard@ifremer.fr (E. Goyard).
} 
filière locale de disposer de $40 \%$ de la diversité allélique de l'espèce) est préconisée de préférence à celle d'animaux sauvages afin de bénéficier (i) de la sélection spontanée qu'elles ont subi lors de leur domestication et (ii) de leur statut sanitaire «specific pathogen free, SPF » (absence de 4 virus : WSV, YHV, IHHNV, TSV) qui limite les risques de transferts de pathogènes.

(c) 2003 Published by Elsevier SAS.

Keywords: Shrimp; Litopenaeus stylirostris; Domestication; Genetic variability; Microsatellite marker

\section{Introduction}

Aquaculture of the Pacific blue shrimp Litopenaeus stylirostris, a species from the Pacific coast of Latin America, is mainly developed in its natural range from animals captured in the wild (either post-larvae or adults used in production hatcheries). In addition, aquaculture of L. stylirostris is also developed in three Pacific Island countries (Hawaii, Tahiti, and New Caledonia) where L. stylirostris was introduced as a candidate species for aquaculture (AQUACOP, 1979; Wyban and Wyban, 1989). In Tahiti, production remains limited because of the lack of land (70 $\mathrm{t}$ year $\left.^{-1}\right)$. In Hawaii, this species is reared by one private company (High Health Aquaculture Inc. (HHA)) in the context of the multi-specific program organised by the United States Department of Agriculture to promote exportation of high valuable "specific pathogen free (SPF)" spawners which reduce the zoosanitary risk linked to international transfers of animals (Lotz et al., 1995): these animals are certified to be free of the four following viruses: Taura Syndrome Virus, Infectious Hypodermal and Hematopoietic Necrosis Virus, White Spot Syndrome Virus, and Yellow Head Virus. This company is the only one in the world to rear and provide SPF lines of L. stylirostris. In New Caledonia, the production, which is based on L. stylirostris only, represents the second exportation of the country and is increasing rapidly (500 $t$ in 1990, $2000 \mathrm{t}$ in 2000 , with a goal of $5000 \mathrm{t}$ in 2005, mainly exported).

From a genetic point of view, the New Caledonian, Tahitian and Hawaiian L. stylirostris industries are all based on closed stocks, which have been domesticated for several generations. More precisely, this species was introduced into New Caledonia via Tahiti from Latin America several times from 1970 to 1980 (AQUACOP, 1979). In Hawaii, a first stock was introduced from Ecuador in 1995 and confirmed "SPF" in the summer of 1996 (Brock pers. com). It was F5 (five generations in culture) at the time of sampling for this study. A second one was introduced from Venezuela to Hawaii through the University of Arizona for primary quarantine in 1999. At the time of sampling, they were F3 at HHA Inc. but probably F25 prior to arrival at HHA Inc.

As for other farmed species, shrimp industries have to integrate newly developed tools such as genetic improvement (Moss, 2002). But, the efficiency of any selective breeding program is linked to the level of genetic variability available in the population under selection. Evidence for loss of genetic variability has been shown in hatchery-propagated aquaculture species and has been known for a long time, and especially in shrimp populations: Sbordoni et al. (1986) pointed out the reduction of heterozygosity in hatchery stocks of Penaeus japonicus and Sunden and Davis (1991) reported similar findings for hatchery stocks of $P$. vannamei. Bierne et al. (2000) observed low levels of allelic diversity in the Tahitian stock of L. stylirostris which is known to have been based on a restricted number of founders at the beginning of their introduction (Michel, pers. com.), when the control of the reproduction was not fully mastered (AQUACOP, 1983), but no comparison with wild stocks was made to demonstrate and quantify the loss of genetic variability in any L. stylirostris domesticated stock.

In the present paper, we compared the genetic diversity of the domesticated broodstocks of New Caledonia, Tahiti, and Hawaii to the genetic diversity of a wild population from Ecuador at three microsatellite loci to assess the potential benefit of a future breeding program using these populations. The number of founders of each strain and the number of parents to be used to transfer the allelic diversity of these strains were also estimated to optimise the future selective breeding programs.

\section{Materials and methods}

\subsection{Sample collection and storage}

The history of New Caledonian populations is uncertain because of the numerous exchanges of animals that have occurred between the hatcheries. Nevertheless, the management of each hatchery tends now to be independent from the others for zoo-sanitary reasons. This partitioning was taken into account in the present study by sampling, in 1999-2000, animals among five stocks that had been propagated independently for 4-7 generations (Table 1): 50 individuals were sampled in three populations at Station d'Aquaculture de Saint-Vincent (SASV-A, SASV-B and SASV-C), in one of the hatchery of Montagnès (MGTS-A) and in one of the hatcheries of Mara (MARA-A). Twenty individuals of the

Table 1

Number of divergent generations between New Caledonian populations

\begin{tabular}{|c|c|c|c|c|c|}
\hline & SASV-A & SASV-B & SASV-C & MARA-A & MTGS-A \\
\hline SASV-A & & $>7$ & $>7$ & $>7$ & $>7$ \\
\hline SASV-B & & & 7 & 7 & 6 \\
\hline SASV-C & & & & 6 & 6 \\
\hline MARA-A & & & & & 4 \\
\hline
\end{tabular}

MTGS-A 
Tahitian strain were sampled at IFREMER-Tahiti facilities in 1999. Fifty individuals were sampled in the two Hawaiian domesticated populations at HHA Inc. facilities in 2001. Thirty wild samples were collected in Ecuador in 1999. Pleopod pieces were removed from each specimen and preserved in $80 \%$ ethanol.

\subsection{DNA extraction}

The procedures for DNA extraction, precipitation and storage were similar to those described in Sambrook et al. (1989): two phenol-chloroform steps allowing protein degradation and DNA isolation and purification, followed by precipitation of the nucleic acid pellet in $100 \%$ ethanol, and washing with $70 \%$ ethanol.

The DNA pellet was then air-dried, resuspended in $200 \mu \mathrm{l}$ of deionised water and stored at $-20{ }^{\circ} \mathrm{C}$. Concentration of DNA extraction was obtained by fluorimetry, and found to be 30-250 ng $\mu^{-1}$.

\subsection{Polymerase chain reaction and electrophoresis of microsatellite loci}

One L. stylirostris microsatellite locus, Styli 19 (tandem repeat: mono and dinucleotide, GenBank accession number: AF097488) (full details in Vonau et al., 1999) and two heterologous loci from P. vannamei, Vanna01 and Vanna02 (tandem repeat: mono and dinucleotide, GenBank accession number: U35314) (Garcia et al., 1996) with primers redesigned to amplify L. stylirostris (Bierne et al., 2000), were used.

The polymerase chain reaction (PCR) was performed in a $30 \mu \mathrm{l}$ reaction volume with a final concentration of $300 \mu \mathrm{M}$ each dNTPs, $1.8 \mathrm{mM} \mathrm{MgCl} 2,0.4 \mu \mathrm{M}$ of each primer, about 10-100 ng of template DNA, 1 X Taq buffer and 0.5 units of Taq polymerase. PCR products were electrophoresed through $6 \%$ denaturing polyacrylamide gels (acrylamide: bisacrylamide, 29:1, 7 M Urea) using 1 X Tris-BorateEDTA buffer. The gels were then silver stained according to Bassam et al. (1991). Ambiguities in reading a genotype were checked by rerunning either the same or a new PCR product.

\subsection{Genetic diversity analyses, variance of allelic frequencies and linkage disequilibrium}

Genetic diversity within populations was estimated by unbiased gene diversity (H) (Nei, 1987). We estimated the overall values for inbreeding coefficient (Fis) as described by Weir and Cockerham (1984), and we used a permutation procedure (1000 permutations) to test whether a particular Fis value was significantly different from 0 . Those calculations were computed with the GENETIX package (Belkhir et al., 2000). In detail, this permutation procedure uses the allelic frequencies estimated from our data set to generate fictive populations under Hardy-Weinberg equilibrium. Each fictive population is constituted of the same number of individual genotypes sampled in the studied population, and the genotypes are defined according both to the allelic frequencies estimated and to the multinomial rule that apply to multi-allelic loci under Hardy-Weinberg equilibrium. The Fis corresponding to each of the 1000 fictive populations is calculated, and a distribution of Fis values expected under Hardy-Weinberg equilibrium is generated. The probability of the observed values to be obtained under Hardy-Weinberg equilibrium is then calculated according to this distribution: if less than $2.5 \%$ of the 1000 values are either superior or inferior to the estimated Fis value in the studied population, it can be concluded that our population exhibit a significant departure to Hardy-Weinberg equilibrium (respectively towards heterozygote deficiency or heterozygote excess, Fis is comprised between 1 and -1 ) with $P<0.05$.

Genetic differentiation (Fst) was estimated between pairs of populations with the estimator $\theta$ of Weir and Cockerham (1984). Fst is a measure of the part of the genetic variance in the data set that is due to genetic differentiation among populations. The significance of the $\hat{\theta}$ values was tested by randomly using the same 1000 permutation procedure described here-below for the Fis, except for Fst, the individuals are permutated between samples and a distribution of the Fst under Hardy-Weinberg (i.e., panmixia) conditions is generated. Then, the estimated $\theta$ values obtained with our samples are considered as significant, with $P<0.05$ when less than $5 \%$ values of the distribution are highest, and the Bonferroni correction for multiple tests was applied (Rice, 1989). Those calculations were also computed with the GENETIX package (Belkhir et al., 2000).

\subsection{Number of wild founders of domesticated population, number of parents to be used to transfer their allelic diversity}

The number of founders of the Hawaiian and New Caledonian populations was estimated from the reduction in the number of alleles in comparison with a control population following the method described by Launey et al. (2001). The mean and the standard deviation of the number of alleles observed in 1000 random subsamples of $n$ individuals taken in the wild Ecuadorian population $(0<n<31)$ were calculated. The expected number of alleles among $n$ individuals could be represented graphically as a function of the number of wild animals sampled. Reciprocally, the number of alleles observed in the domesticated population provided an estimate of the number of founders, i.e., the number of wild animals presenting the same allelic diversity.

A similar method was used to assess the number of spawners of each domesticated strain that should be mated to allow no loss of allelic diversity. For each strain, 1000 random subsamples of $n$ individuals were taken $(0<n<31)$ and the number of alleles that they presented in each locus was expressed in percentage of the allelic diversity available in 
this strain. In total, 3000 successive evaluations of the relative allelic diversity available in these subsamples were obtained by gathering the information given by the different loci. The mean, standard deviation and minimum values were calculated from these 3000 evaluations and plotted for each size of subsamples.

\section{Results}

\subsection{Allelic diversity}

Allele frequencies are given in Table 2. At locus Styli 19, two alleles very close in size (approximately 230 and

Table 2

Allele frequencies and heterozygosities on the three studied loci. The number of observations $(N)$, the unbiased mono- and multi-locus heterozygosities (Hn.b.), the observed mono- and multi-locus heterozygosities (Hobs.) and multi-locus Fis are given for each population

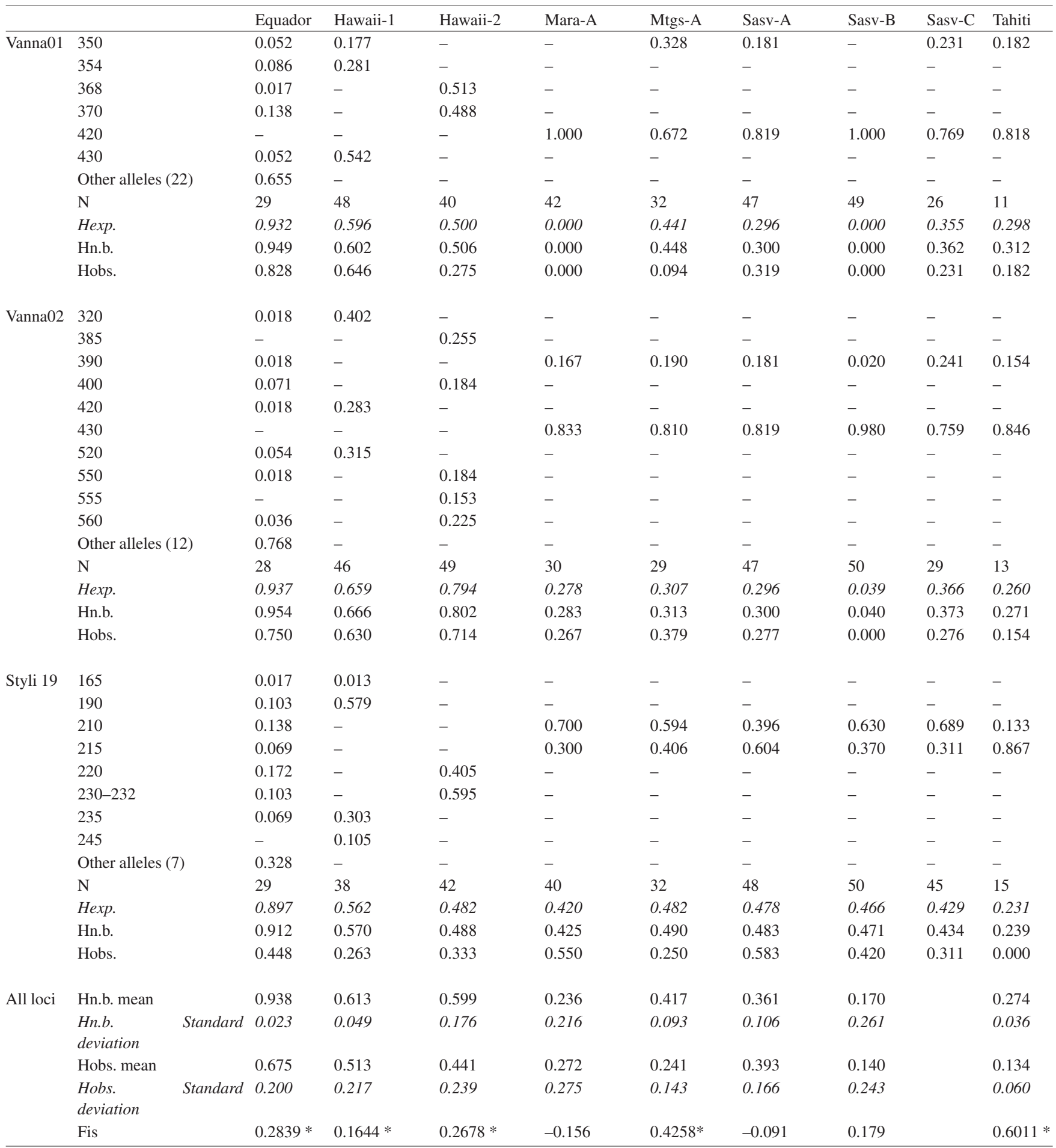

* Significant Fis valves $(P=0.05)$ 
232 pairs of bases) are present in only one population (Hawaii-2). As they were difficult to distinguish, they were put together in the same class of alleles in order to avoid misreading of the gels.

The allelic diversity available in the wild on the three studied loci ranges between 14 and 27 alleles per locus. Ten percent of this diversity is available in the New Caledonian and Tahitian populations that share the same alleles (two alleles per locus). The two populations from Hawaii did not share any common allele and each one presents a higher allelic diversity than the New Caledonian and Tahitian ones (respectively 3.7 and 3 alleles per locus in average for Hawaii-1 and Hawaii-2).

Only one allele at one locus (allele 350 on locus Vanna01) was shared between French populations and Hawaiian populations.

\subsection{Heterozygosity}

Mono-locus unbiased and observed heterozygosities are given in Table 2. Multi-locus unbiased and observed heterozygosities range respectively from $0.17( \pm 0.26$ standard deviation) to 0.94 ( \pm 0.02 standard deviation) and from 0.13 ( \pm 0.06 standard deviation) to $0.67( \pm 0.20$ standard deviation) (Table 2). The heterozygote deficiencies (Fis) are significant in six populations $(P<0.05)$.

\subsection{Differentiation between populations}

Fst values are significant between all pairs of populations $(P<0.05)$ except for two pairs (Mgts-A and SASV-C on one side and for SASV-A and Tahiti for the other side) (Table 3).

\subsection{Number of founders}

The number of alleles observed at each locus appears as a function of the size of the subsample of the wild population (Fig. 1). The mean number of founders is three for each domesticated strain (Table 4). In the most favourable case, the number of founders could be 8,9 and 4 for the strains Hawaii-1, Hawaii-2 and New Caledonia, respectively.

\subsection{Number of parents to mate not to loose allelic diversity}

The average and minimum diversities sampled among one to thirty individuals randomly chosen in each domesticated

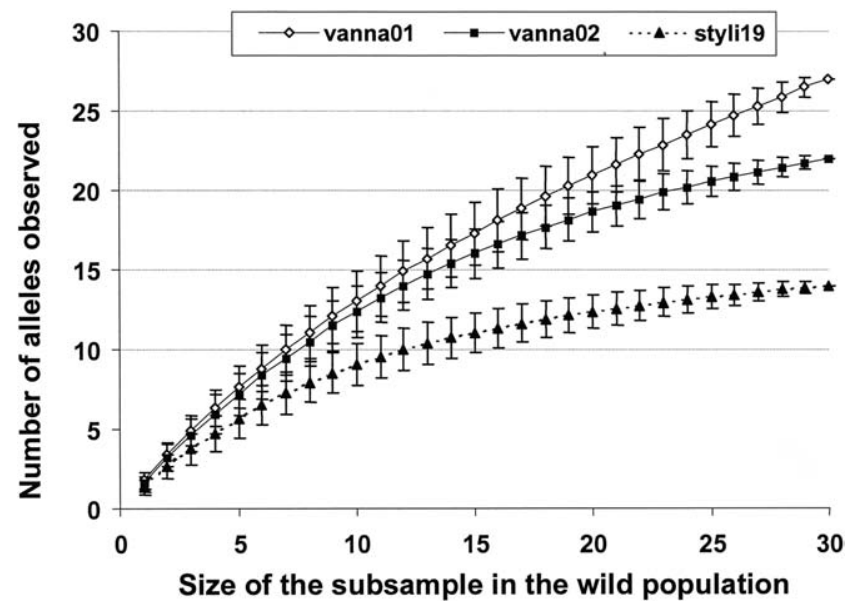

Fig. 1. Reduction in the number of alleles observed in the three loci studied as a function of the size of the samples, among the wild Ecuadorian population.

strain are given (Fig. 2). In average, $90 \%$ of the allelic diversity is reached by sampling eight, four, and eight individuals for Hawaii-1, Hawaii-2 and New Caledonian populations, respectively. It is necessary to sample 22, 12, and 22 individuals, respectively, to be sure to get at least $75 \%$ of the allelic diversity available in these strains.

\section{Discussion}

In all but three populations (SASV-A, SASV-B and MARA-A), Fis are significant: the observed heterozygosity is lower than the expected heterozygosity calculated with the allele frequencies on the hypothesis of panmixy (unbiased heterozygosity). Four potential causes may induce such a phenomenon in a given population. The first is a technical artifact linked to the occurrence of null alleles (undetected alleles that lead to classifying some true heterozygotes as false homozygotes). Three other potential causes, which are based on the biology of the studied population, can generally be advanced: (i) "Wahlund effect" (i.e., an overestimation of the expected rate of heterozygotes due to the fact that the studied sample is actually issued from several genetically distinct populations, which leads to the false conclusion that there are less heterozygotes than it should be at Hardy-

Table 3

Genetic differentiation (Fst) between pairs of populations estimated by the $\theta$ of Weir and Cockerham (1984). Non-significant values are printed in italic $(P>0.05)$

\begin{tabular}{|c|c|c|c|c|c|c|c|c|c|}
\hline & Equador & Hawaii-1 & Hawaii-2 & Mara-A & Mtgs-A & Sasv-A & Sasv-B & Sasv-C & Tahiti \\
\hline Equador & - & 0.182 & 0.170 & 0.407 & 0.291 & 0.353 & 0.476 & 0.307 & 0.321 \\
\hline Hawaii-1 & & - & 0.391 & 0.564 & 0.463 & 0.509 & 0.613 & 0.480 & 0.500 \\
\hline Hawaii-2 & & & - & 0.570 & 0.478 & 0.519 & 0.620 & 0.491 & 0.510 \\
\hline Mara-A & & & & - & 0.098 & 0.113 & 0.032 & 0.047 & 0.318 \\
\hline Mtgs-A & & & & & - & 0.036 & 0.135 & -0.004 & 0.142 \\
\hline Sasv-A & & & & & & - & 0.118 & 0.064 & 0.041 \\
\hline Sasv-B & & & & & & & - & 0.113 & 0.333 \\
\hline Sasv-C & & & & & & & & - & 0.204 \\
\hline Tahiti & & & & & & & & & - \\
\hline
\end{tabular}


Table 4

Number of alleles observed in locus and estimates of the numbers of founders in domesticated strains

\begin{tabular}{|c|c|c|c|c|c|c|}
\hline & & & Vanna01 & Vanna02 & Styli 19 & All loci \\
\hline Ecuador & Number of alleles observed & & 27 & 22 & 14 & 63 \\
\hline \multirow[t]{4}{*}{ Hawaii-1 } & Number of alleles observed & & 3 & 3 & 4 & 10 \\
\hline & Estimate of founders & Minimum & 2 & 2 & 2 & 2 \\
\hline & & Mean & 2 & 2 & 3 & 3 \\
\hline & & Maximum & 5 & 5 & 8 & 8 \\
\hline \multirow[t]{4}{*}{ Hawaii-2 } & Number of alleles observed & & 2 & 5 & 3 & 10 \\
\hline & Estimate of founders & Minimum & 1 & 3 & 2 & 3 \\
\hline & & Mean & 2 & 3 & 2 & 3 \\
\hline & & Maximum & 4 & 9 & 6 & 9 \\
\hline \multirow[t]{3}{*}{ New Caledonia } & Number of alleles observed & & 2 & 2 & 2 & 6 \\
\hline & Estimate of founders & Minimum & 2 & 2 & 2 & 2 \\
\hline & & Maximum & 4 & 4 & 4 & 4 \\
\hline
\end{tabular}

Weinberg equilibrium; Hartl and Clarck, 1997), (ii) selection of specific alleles and (iii) inbreeding. In the present study, selection can hardly be suspected as microsatellite markers are generally considered to be neutral and therefore not selectable. The three other potential causes have to be weighted depending on the stock being considered. "Wahlund effect" is unlikely to be a good explanation for hatcherypropagated populations whose histories are well known, but it may explain the deficiency observed in the Ecuadorian wild samples. The occurrence of null alleles may also explain the heterozygotes deficiencies in the wild Ecuadorian population and in the Hawaiian populations. But the fact that no deficiency is observed in three domesticated populations of New Caledonia (SASV-A, SASV-B and MARA-A) tends to show that there is no null allele among the six New Caledonian and Tahitian populations as they share the same alleles. Therefore, this supports the hypothesis that the heterozygotes deficiency which affects SASV-C, MGTS-A and Tahiti is due to inbreeding whose likelihood is increased by the small number of parents at each generation, as may be the case in Hawaii.

Although differentiation of several populations of L. stylirostris has been demonstrated in Latin America (Aubert and Lightner, 2000), the allelic diversity available in Ecuador is likely equivalent to that of the wild founder populations of the domesticated populations studied in this paper. Therefore, the loss of genetic variability in domesticated stocks, which had been previously observed for P. japonicus (Sbordoni et al., 1986) and for L. vannamei (Sunden and Davis, 1991) is now demonstrated for L. stylirostris by the present study.

The fact that the same alleles are found in the Tahitian and the New Caledonian stocks and the fact that the species was introduced in New Caledonia via Tahiti suggest that most alleles were lost before the partitioning of these stocks. This would explain why the larger number of spawners used by each New Caledonian hatchery to meet the demand in postlarvae does not result in greater allelic diversity than in the
Tahitian stock where less spawners are used. Nevertheless, despite this great number of spawners (several thousands per hatchery cycle), some differentiation between New Caledonian populations has already appeared within a few generations (four to seven). This shows that the effective number of spawners $(\mathrm{Ne})$, i.e., the number of spawners that really participate in the maintenance of the populations, is very small and is likely to increase inbreeding.

The negative impact of inbreeding on the capacity to adapt to new breeding conditions has been demonstrated in $L$. vannamei by De Freitas and Junior (2002). Bierne et al. (2000) had also found that the most inbred individuals within the Tahitian L. stylirostris population had poorer growth performance. Nevertheless, populations of New Caledonia do not show any depression of performance and demonstrate high productivity (Lucien-Brun, 2001). At a population scale and on a long-term basis, inbreeding could have purged the domesticated populations of deleterious genes of the species and induced an indirect positive effect by easing spontaneous selection for better performances in the specific rearing environments.

The low allelic diversity exposes the domesticated populations studied to the risk of being unable to respond to new selective pressures due to controlled or uncontrolled changes in the environment. This risk is illustrated by the realised heritability of growth rate obtained in an experimental selective breeding program on the Tahitian strain (Goyard et al., 2001) which is relatively low when compared to other experimental results on other shrimp species (Hetzel et al., 1999; Benzie, 1997). Similarly, this low diversity may endanger the cultivated strains in case of introduction of a new pathogen.

As a consequence, this study argues for an introduction of variability into the domesticated populations studied, and especially in the New Caledonian one on which an important industry is based. Since the same alleles are found in the Tahitian and the New Caledonian stocks, introduction of the Tahitian population into New Caledonia would not increase the allelic diversity of the New Caledonian stocks. The strat- 

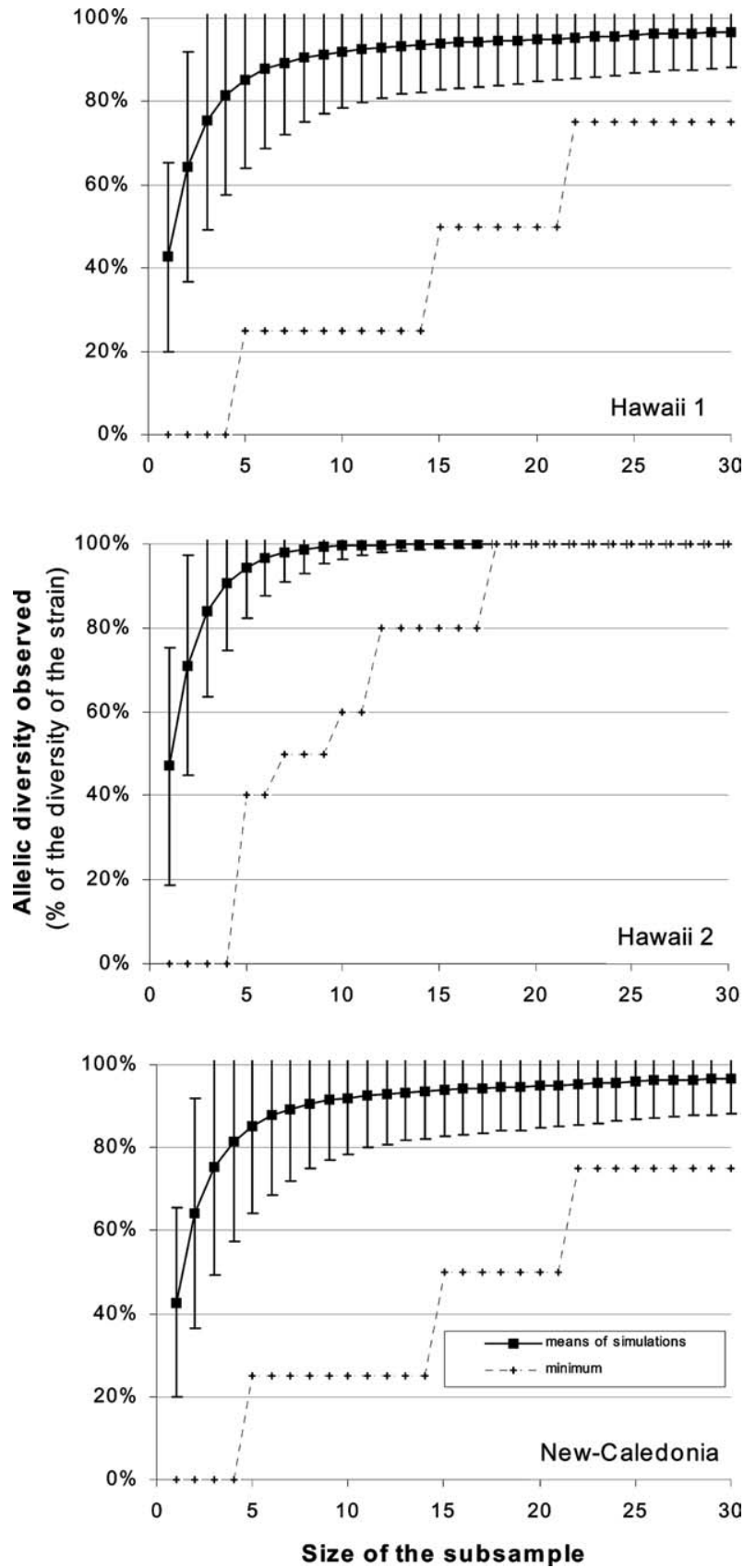

Fig. 2. Average and minimum percentage of allelic diversity of the strains: Hawaii-1, Hawaii-2 and New Caledonia, transferred by a limited number of effective spawners sampled randomly.

egy of importing the two Hawaiian SPF strains into New Caledonia may be more efficient than introducing wild diversity because the genetic gain due to domestication would not be lost: indeed the Hawaiian strains have also demonstrated high performances (Wyban, unpublished data). In addition, the sanitary status of the Hawaiian strains (SPF) limits the zoo-sanitary risks linked to international transfers, which have to be done in the respect of ICES recommendations (International Council for the Exploration of the Sea). The very low proportion of alleles shared by the New Caledonian and the two Hawaiian populations (only one allele among 25 on three loci) illustrates that genetic drift does not produce the same results on independent populations. Therefore, mixing the two Hawaiian populations together could lead to a composite domesticated population which would present $32 \%$ of the allelic diversity available in the wild. Similarly, introducing the two Hawaiian strains into New Caledonia would allow the local industry to exploit $40 \%$ of the allelic diversity available in the wild. The most likely number of founders would increase from 2 to 8 , and the maximum number of founders from 4 to 21 .

Despite the relatively low number of founders of each population, the objective of transferring most of the residual variability will only be reached by sampling the genetic variability through a number of spawners, which is much higher than the number of founders. Twelve to twenty-two effective spawners should be used to guaranty the transfer of $75 \%$ of the Hawaiian allelic diversity. This apparent contradiction is due to the variance of the allelic frequencies, as rarer alleles are less likely to be sampled.

As a conclusion, the management of the present variability and of the potentially imported variability would have to take into account the positive correlation between heterozygosity and growth rate (Bierne et al., 2000). This argues for the maintenance of the three genetically different domesticated strains that could be mated at each generation to produce commercial 2-ways or 3-ways hybrids whose heterozygosity would be higher than in the wild. This strategy to exploit the genetic resources available in the farms remains to be tested.

\section{Acknowledgements}

The present study was enabled thanks to Jean Goguenheim who participated in the sampling of the wild Ecuadorian population, and to the three private hatcheries of New Caledonia who provided the samples of their broodstock.

\section{References}

AQUACOP, 1979. Proceedings of the Tenth Annual Meeting of World Mariculture Society. Penaeid reared broodstock: closing the cycle of $P$. monodon, $P$. stylirozstris and $P$. vannamei. Proc. $10^{\text {th }}$ Annual Meeting of the World Aquaculture Society, 10, pp. 445-452.

AQUACOP, 1983. Constitution of broodstock, maturation, spawning and hatchery system for penaeid shrimps in the Centre Oceanologique du Pacifique. In: McVey, J.P. (Ed.), CRC Handbook of Mariculture, vol. 1: Crustacean Aquaculture. CRC Press, Miami, FL, USA, pp. 105-121.

Aubert, H., Lightner, D.V., 2000. Identification of genetic populations of the Pacific blue shrimp Penaeus stylirostris of the Gulf of California, Mexico. Mar. Biol. 137, 875-885.

Bassam, B.J., Caetano-Anolles, G., et al., 1991. Fast and sensitive silverstaining of DNA in polyacrylamide gels. Anal. Biochem. 196, 80-83.

Belkhir, K., Borsa, P., Chikhi, L., Raufaste, N., Bonhomme, F., 2000. GENETIX 4.02, logiciel sous Windows TM pour la génétique des populations. Laboratoire Génome, Populations, Interactions, CNRS UPR 9060, Université de Montpellier II, Montpellier (France).

Benzie, J.A.H., 1997. A review of the effect of genetics and environment on the maturation and larval quality of the giant tiger prawn Penaeus monodon. Aquaculture 155, 69-85. 
Bierne, N., Beuzart, I., Vonau, V., Bonhomme, F., Bédier, E., AQUACOP, 2000. Microsatellite-associated heterosis in hatchery-propagated stocks of the shrimp Penaeus stylirostris. Aquaculture 184, 203-219.

De Freitas, P.D., Junior, P.M.G., 2002. PCR-based VNTR core sequence analysis for inferring genetic diversity in the shrimp Litopenaeus vannamei. Genet. Mol. Biol. 25, 431-434.

Garcia, D.K., Dhar, A., Alcivar-Warren, A.A., 1996. Molecular analysis of a RAPD marker (B20) reveals presence of two microsatellites and differential mRNA expression in Penaeus vannamei. Mol. Mar. Biol. Biotechnol. 5, 1-83.

Goyard, E., Patrois, J., Peignon, J.M., Vanna, V., Dufour, R., Viallon, J., Bédier, E., 2001. Selection for better growth of Penaeus stylirostris in Tahiti and New Caledonia. Aquaculture 204, 461-468.

Hartl, D.L., Clarck, A.G., 1997. Principles of Population Genetics. third ed. Sinauer Associates Publ., Inc., Sunderland, MA (USA).

Hetzel, D.J.S., Crocos, P.J., Davis, G.P., Moore, S.S., Preston, N.C., 1999. Response to selection and heritability for growth in the Kuruma prawn, Penaeus japonicus. Aquaculture 181, 215-223.

Launey, S., Barré, M., Gérard, A., Naciri-Graven, Y., 2001. Population bottleneck and effective size in Bonamia ostreae-resistant populations of Ostrea edulis as inferred by microsatellite markers. Genet. Res. 78, 259-270.

Lotz, J.M., Browdy, C., Carr, W., Frelier, P., Lightner, D., 1995. USMSFP suggested procedures and guidelines for assuring the specific pathogen free status of shrimp broodstock and seed. Proceedings of the Special Session. In: Browdy, C.L., Hopkins, J.S. (Eds.), Aquaculture 1995. World Aquaculture Society, Baton Rouge, LA, USA.
Lucien-Brun, H., 2001. Shrimp farming in New Caledonia: successful, integrated industry. Global Aquac. Adv. 4, 63-64.

Moss, S.M., 2002. Marine shrimp farming in the western hemisphere: past problems, present solutions, and future visions. Rev. Fish. Sci. 10, 601-620.

Nei, M., 1987. Molecular Evolutionary Genetics. Columbia University Press, New York.

Rice, W.R., 1989. Analysing tables of statistical tests. Evolution 43, 223225.

Sambrook, J., Fritsch, E.F., Maniatis, T., 1989. Molecular Cloning. second ed. Cold Spring Harbor Laboratory, Cold Spring Harbor, New York.

Sbordoni, V., de Matthaeis, E., Sbordoni, M.C., La Rosa, G., Mattoccia, M., 1986. Bottleneck effects and the depression of genetic variability in hatchery stocks of Penaeus japonicus (Crustacea, Decapoda). Aquaculture 57, 239-251.

Sunden, S.L.F., Davis, S.K., 1991. Evaluation of genetic variation in a domestic population of $P$. vannamei (Boone): a comparison with three natural populations. Aquaculture 97, 131-142.

Vonau, V., Ohresser, M., Bierne, N., Delsert, C., Beuzart, I., Bedier, E., Bonhomme, F., 1999. Three polymorphic microsatellites in the shrimp Penaeus stylirostris. Anim. Genet. 30, 234-235.

Weir, B.S., Cockerham, C.C., 1984. Estimating $F$-statistics for the analysis of population structure. Evolution 38, 1358-1370.

Wyban, J.A., Wyban, C.A., 1989. Aquaculture in Hawaii: past, present and future. Advances in Tropical Aquaculture, Tahiti March, 1989. AQUACOP IFREMER Actes de Colloque, 37-43. 